\title{
Strategy to Detect Genetically Modified Bacteria Carrying Tetracycline Resistance Gene in Fermentation Products
}

\author{
Marie-Alice Fraiture $^{1} \cdot$ Marie Deckers ${ }^{1} \cdot$ Nina Papazova ${ }^{1} \cdot$ Nancy H. C. Roosens ${ }^{1}$ (i)
}

Received: 2 March 2020 / Accepted: 14 June 2020 / Published online: 7 July 2020

(C) The Author(s) 2020

\begin{abstract}
Unexpected contaminations of unauthorized genetically modified microorganisms (GMM) harbouring antimicrobial resistance (AMR) genes in food and feed enzymes, additives and flavourings commercialized on the European market have recently alerted the competent authorities regarding the food and feed safety. At the control level, we have therefore proposed a PCR-based strategy as first line screening targeting GMM carrying AMR genes in order to help enforcement laboratories. The potential presence of frequently used AMR genes is first investigated, using real-time PCR. In case of a suspicious matrix, the full-length of the detected AMR genes is then determined, using conventional PCR followed by Sanger sequencing, allowing to support the competent authorities in their evaluation related to potential health risks. In this study, PCR methods targeting an additional key AMR gene, being the tet- $L$ gene (GenBank: D00946.1) conferring a resistance to tetracycline, were developed and successfully assessed in terms of specificity, sensitivity and applicability. In integrating these PCR methods, the proposed PCR-based strategy, initially targeting two key AMR genes conferring a resistance to chloramphenicol (GenBank: NC_002013.1) and kanamycin (GenBank: M19465.1), is consequently strengthened, allowing the coverage of a larger spectrum of potential GMM contaminations in microbial fermentation products.
\end{abstract}

Keywords Tetracycline resistance gene - Food and feed enzymes · Additives and flavourings · Genetically modified microorganisms $\cdot$ PCR-based strategy $\cdot$ Full-length AMR gene $\cdot$ Food and feed safety

\section{Introduction}

Recently, the unauthorized presence of living strains or associated recombinant DNA from genetically modified microorganisms (GMM) have been discovered in microbial fermentation products commercialized on the European (EU) food and feed market (RASFF portal). For instance, in 2014, 2018

Electronic supplementary material The online version of this article (https://doi.org/10.1007/s12161-020-01803-6) contains supplementary material, which is available to authorized users.

Nancy H. C. Roosens

Nancy.Roosens@sciensano.be

Marie-Alice Fraiture

Marie-Alice.Fraiture@sciensano.be

Marie Deckers

Marie.Deckers@sciensano.be

Nina Papazova

Nina.Papazova@sciensano.be

1 Sciensano, Transversal Activities in Applied Genomics (TAG), J. Wytsmanstraat 14, 1050 Brussels, Belgium and 2019, feed additives composed of vitamin B2 were contaminated by a genetically modified (GM) vitamin B2producing Bacillus subtilis (RASFF2014.1249, RASFF2014.1360, RASFF2014.1657, RASFF2018.2755, RASFF2019.0793 and RASFF2019.3216). In addition, in 2019, a food enzyme preparation containing a protease was contaminated by a GM protease-producing Bacillus velezensis strain (RASFF2019.3332). These notifications have consequently raised two main concerns. First, at the EU legislation level, such GMM in commercialized microbial fermentation products fall under the EU regulation EC/1829/2003 related to the commercialization of genetically modified organisms (GMO) intended to the food and feed chain. Since no request for this type of authorization has nowadays officially been approved, such GMM are thus considered as unauthorized. Second, at the food and feed chain safety level, the unexpected presence of antimicrobial resistance (AMR) genes, frequently harboured as selection marker by such GMM to facilitate the production processes of microbial fermentation products, in the food and feed chain concerns the competent authorities. More precisely, it increases considerably the likelihood of horizontal AMR gene transfers to pathogens and gut 
microbiota, especially in presence of the full-length AMR gene and the living GMM carrying the AMR gene (Bacanli and Basacan 2019; Fraiture et al. 2020a, 2020b, 2020c; Munita and Arias 2016; Regulation (EC) 1829/ 2003; Rozwandowicz et al. 2018; Sharma et al. 2018; von Wrighta and Bruce 2003; Xiong et al. 2018).

In this context, the interest of the competent authorities to control potential GMM contaminations in food and feed enzymes, additives and flavourings is increasing. Nonetheless, nowadays, its implementation by enforcement laboratories is hampered mainly due to the confidentiality of the related GMM dossiers. Currently, only a few methods are available, which are specific to two GM bacterial strains previously characterized from commercialized contaminated microbial fermentations products (Barbau-Piednoir et al. 2015a, 2015b; Fraiture et al. 2020c; Paracchini et al. 2017). On this basis, enforcement laboratories have thus currently at their disposal no relevant tool to perform a first line screening to target a larger number of possible GMM contaminations in microbial fermentations products.

To overcome it, we have therefore recently collected and analysed 241 publicly available patents in order to identify key targets carried by a large spectrum of GMM used to produce microbial fermentation products. It results in the identification of key AMR genes frequently harboured by such GMM, including a chloramphenicol acetyl-transferase (cat) gene (GenBank: NC_002013.1), conferring a resistance to chloramphenicol ( $\mathrm{CmR})$, and an aminoglycoside adenyltransferase (aadD) gene (GenBank: M19465.1), conferring a resistance to both kanamycin and neomycin (KanR). The combination of only these two AMR genes allowed covering $72.6 \%$ of the inventoried patents. On this basis, a PCRbased strategy was proposed to first screen the potential presence of these key AMR genes, using real-time-PCR, and then to assess their full-length, using conventional PCR associated to Sanger sequencing. The competent authorities could therefore be informed about both the potential presence of GMM in the tested matrices as well as the potential associated health risks (Fraiture et al. 2020a, 2020b).

With the aim to strengthen this first line screening analysis in term of GMM coverage, the tet- $L$ gene (GenBank: D00946.1), conferring a resistance to tetracycline (TetR), was selected in this study as an additional key target for the previously proposed PCR-based strategy. According to Fraiture et al. (2020b), this AMR gene, originating from the pLS1 plasmid, associated to the previously selected cat (GenBank: NC_002013.1) and aadD (GenBank: M19465.1) genes allowed to cover $88 \%$ of the inventoried patents. The performance of the corresponding PCR methods, including the specificity, sensitivity and applicability, was tested in order to be easily implemented by enforcement laboratories. Therefore, enforcement laboratories will be able to actively support the competent authorities to monitor the GMM contamination of microbial fermentation products. Moreover, it will allow guaranteeing the freedom of choice as well as the food and feed safety to consumers.

\section{Materials and Methods}

\section{In Silico Analysis of the Selected tetL Gene}

The sequence from the tetl gene conferring TetR (GenBank: D00946.1) was blasted against the NCBI database (Refseq genomic) with non-default parameters (word, 256; targets, 20.000; threshold, 1; organism, fungi, yeast, Acidobacteria, Aquificae, Caldiserica, Caldithrix, Chrysiogenetes, Coprothermobacterota, Deferribacteres, Dictyoglomi, Elusimicrobia, FCB group, Fusobacteria, Nitrospinae/Tectomicrobia group, Nitrospirae, Proteobacteria, PVC group, Spirochaetes, Synergistetes, Terrabacteria group, Thermodesulfobacteria, Thermotogae, unclassified Bacteria, Eubacteria environmental samples) (Supplementary file 1).

\section{Real-Time PCR}

The TaqMan ${ }^{\circledR}$ real-time PCR tetL marker, previously developed by Turgeon et al. 2008, was selected to target the tetL gene conferring TetR (GenBank: D00946.1) (Table 1). DNA from collected materials was tested in 2, 3 or 12 replicates (Tables 2, 3 and 4). Each real-time PCR assay was applied on a $25-\mu$ l reaction volume containing $1 \mathrm{X}$ TaqMan ${ }^{\circledR}$ PCR Mastermix (Diagenode), $400 \mathrm{nM}$ of each primer (Eurogentec), $200 \mathrm{nM}$ of the probe and $5 \mu \mathrm{l}$ of DNA. The real-time PCR program consisted of a single cycle of DNA polymerase activation for $10 \mathrm{~min}$ at $95{ }^{\circ} \mathrm{C}$ followed by 45 amplification cycles of $15 \mathrm{~s}$ at $95{ }^{\circ} \mathrm{C}$ (denaturing step) and $1 \mathrm{~min}$ at $64^{\circ} \mathrm{C}$ (annealing-extension step). All runs were performed on an a CFX96 Touch Real-Time PCR Detection System (BioRad). A no template control (NTC) was included in each assay.

\section{Conventional PCR}

A pair of primers, namely tetL-F1 and tetL-R1, were designed to cover the majority of the tet $L$ gene conferring TetR (GenBank: D00946.1) (Table 1). DNA from collected materials was tested in 2 or 12 replicates (Tables 2, 3 and 4, Supplementary files 2-4). Each PCR assay was applied on a $25-\mu 1$ reaction volume containing $1 \mathrm{X}$ Green DreamTaq PCR Master Mix (ThermoFisher Scientific), $400 \mathrm{nM}$ of each primer (Eurogentec) and $5 \mu \mathrm{l}$ of DNA. The PCR program consisted of a single cycle of $1 \mathrm{~min}$ at $95{ }^{\circ} \mathrm{C}$ (initial denaturation) followed by 35 amplification cycles of $30 \mathrm{~s}$ at $95{ }^{\circ} \mathrm{C}$ (denaturation), $30 \mathrm{~s}$ at $60{ }^{\circ} \mathrm{C}$ 
Table 1 Oligonucleotides used for the real-time PCR and conventional PCR methods targeting the tet- $L$ gene (TetR-1). On the targeted sequence, the location of the used oligonucleotides is indicated. For the real-time
PCR method, the primers and probe are indicated in lowercase and in bold. For the conventional PCR method, the couple of primers is underlined

Targeted sequences

$>$ tet- $L$ gene conferring a resistance to TetR (GenBank: D00946.1)

TTAGAAATCCCTTTGAGAATGTTTATATACATTCAAGGTAACCAGCCAACTAATGACAATGATTCCTGAAAAAAGTAATAACAAAT

TACTATACAGATAAGTTGACTGATCAACTTCCATAGGTAACAACCTTTGATCAAGTAAGGGTATGGATAATAAACCACCTACAA TTGCAATACCTGTTCCCTCTGATAAAAAGCTGGTAAAGTTAAGCAAACTCATTCCAGCACCAGCTTCCTGCTGTTTCAAGCTA CTTGAAACAATTGTTGATATAACTGTTTTGGTGAACGAAAGCCCACCTAAAACAAATACGATTATAATTGTCATGAACCATGAT GTTGTTTCTAAAAGAAAGGAAGCAGTTAAAAAGCTAACAGAAAGAAATGTAACTCCGATGTTTAACACGTATAAAGGACCTCTT CTATCAACAAGTATCCCACCAATGTAGCCGAAAATAATGACACTCATTGTTCCAGGGAAAATAATTACACTTCCGATTTCGGCA GTACTTAGCTGGTGAACATCTTTCATCATATAAGGAACCATAGAGACAAACCCTGCTACTGTTCCAAATATAATTCCCCCACAA AGAACTCCAATCATAAAAGGTATATTTTTCCCTAATCCGGGATCAACAAAAGGATCTGTTACTTTCCTGATATGTTTTACAAAT ATCAGGAATGACAGCACGCTAACGATAAGAAAAGAAATGCTATATGATGTTGTAAACAACATAAAAAATACAATGCCTACAGAC ATTAGTATAATTCCTTTGATATCAAAATGACCTTTTATCCTTACTTCTTTCTTTAATAATTTCATAAGAAACGGAACAGTGATA ATTGTTATCATAGGAATGAGTAGAAGATAGGACCAATGAATATAATGGGCTATCATTCCACCAATCGCTGGACCGACTCCTTCT CCCATGGCTACTATCGATCCAATAAGACCAAATGCTTTACCCCTATTTTCCTTTGGAATATAGCGCGCAACTACAACCATTACG AGTGCTGGAAATGCAGCTGCACCAGCCCCTTGAataaaacgagccataataagtaaggaaaagAAAG

AATGGccaacaaacceaattaccgaccegaaacaaTTTATTATAATTCCAAATAggagtaacettttgatgectaattgaTCAGATAGCTTTCCATATACAGCTGT TCCAATGGAAAAGGTTAACATAAAGGCTGTGTTCACCCAGTTTGTACTCGCAGGTGGTTTATTAAAATCATTTGCAATATCAGGT AATGAGACGTTCAAAACCATTTCATTTAATACGCTAAAAAAAGATAAAATGCAAAGCCAAATTAAAATTTGGTTGTGTCGTAAA TTCGATTGTGAATAGGATGTATTCAC

\begin{tabular}{|c|c|c|c|c|}
\hline \multirow[t]{2}{*}{ Methods } & \multicolumn{2}{|c|}{ Oligonucleotides } & \multirow[t]{2}{*}{ Expected amplicon size } & \multirow[t]{2}{*}{ References } \\
\hline & Names & Sequences & & \\
\hline \multirow[t]{3}{*}{ Real-time PCR } & tetL-F & ATAAAACGAGCCATAATAAGTAAGGAAAAG & \multirow[t]{3}{*}{$114 \mathrm{bp}$} & \multirow[t]{2}{*}{ Turgeon et al. 2008} \\
\hline & tetL-P & FAM-CCAACAAACCCAATTACCGACCCGAAACAA-TAMRA & & \\
\hline & tetL-R & TCAATTAGGCATCAAAAGGTTACTCC & & \\
\hline \multirow[t]{2}{*}{ Conventional PCR } & tetL-F1 & TTGCAATACCTGTTCCCTCTG & \multirow[t]{2}{*}{$1053 \mathrm{bp}$} & \multirow[t]{2}{*}{ This study } \\
\hline & tetL-R1 & ACTGGGTGAACACAGCCTTT & & \\
\hline
\end{tabular}

(annealing) and $1 \mathrm{~min}$ at $72{ }^{\circ} \mathrm{C}$ (extension) and finishing by a single cycle of $5 \mathrm{~min}$ at $72{ }^{\circ} \mathrm{C}$ (final extension). The run was performed on a Swift MaxPro Thermal Cycler (Esco). A NTC was included in each assay. The final PCR products were visualized by electrophoresis using the Tapestation 4200 device with the associated D1000 and D5000 Screen Tapes and reagents (Agilent) (Supplementary files 2-4). Sequencing of final PCR products, earlier purified using USB ExoSAP-IT PCR Product Cleanup (Affymetrix), was performed on a Genetic Sequencer 3130XL using the Big Dye Terminator Kit v3.1 (Applied Biosystems). The generated sequences were basted against NCBI database (nr/nt) with default parameters and aligned using NCBI global alignment and MUSCLE (Supplementary files 5-6).

\section{Materials}

Ninety-one wild-type bacterial and fungal strains were collected from Sciensano, the Belgian coordinated collections of microorganisms, the Research Institute for Agriculture, Fisheries and Food, the Convention of Biological Diversity, the American Type Culture Collection and the Deutsche Sammlung von Mikroorganismen und Zellkulturen GmbH (Table 2). These microbial strains correspond to the majority of microorganisms reported by EFSA Panel on Biological Hazards (2017) as being used by the food and feed industry to produce food and feed additives, enzymes and flavourings (Deckers et al. 2020; EFSA Panel on Biological Hazards 2017; Fraiture et al. 2020a, 2020b). Based on the RASFF2019.3332, Bacillus velezensis strains were also included (Fraiture et al. 2020c).

For the positive controls carrying the tet $L$ gene (GenBank: D00946.1), the vitamin B2-producing GM B. subtilis RASFF2014.1249 strain was collected from Sciensano (Tables 2 and 3, Supplementary files 2-3) (Barbau-Piednoir et al. 2015a, 2015b; Paracchini et al. 2017) and the plasmid pLS1 collected from the Université Laval (Table 2) (Lacks et al. 1986; Turgeon et al. 2008). From the GM B. subtilis RASFF2014.1249 strain, DNA at different estimated full genome copy numbers $\left(55 \times 10^{3}, 550,55,11,5,1\right.$ and 0$)$ was prepared according to Fraiture et al. (2020a, 2020b) to assess the sensitivity of the real-time and conventional PCR methods (Table 3, Supplementary files 3, 7-8). For each of these estimated full genome copy number, 12 replicates were tested. On this basis, the limit of detection $\mathrm{LOD}_{95 \%}$, defined as the number of copies of the target required to ensure a $95 \%$ probability of detection (POD), was determined as previously described (Uhlig et al. 2015; Grohmann et al. 2016; https://quodata.de/ 
Table 2 List of wild-type microorganisms used for the specificity assessment of the real-time PCR and conventional PCR methods targeting the tet- $L$ gene (GenBank: D00946.1). The presence and absence of amplification are respectively symbolized by "+" and "-.". For the conventional PCR method, a positive amplification is symbolized by " $(+)$ " in case the corresponding sequence does not present $100 \%$ of identity and recovery to the targeted AMR gene (Supplementary files 5-6). In

\begin{tabular}{|c|c|c|c|c|c|}
\hline Kingdom & Genus & Species & Strain number & Real-time PCR & Conventional PCR \\
\hline \multirow{38}{*}{ Fungi } & Aspergillus & acidus & IHEM 26285 & - & - \\
\hline & Aspergillus & aculeatus & IHEM 05796 & - & - \\
\hline & Aspergillus & fijiensis & IHEM 22812 & - & - \\
\hline & Aspergillus & melleus & IHEM 25956 & - & - \\
\hline & Aspergillus & niger & IHEM 25485 & - & - \\
\hline & Aspergillus & oryzae & IHEM 25836 & - & - \\
\hline & Boletus & edulis & MUCL 043104 & - & - \\
\hline & Candida & cylindracea & MUCL 041387 & - & - \\
\hline & Candida & rugosa & IHEM 01894 & - & - \\
\hline & Chaetomium & gracile & MUCL 053569 & - & - \\
\hline & Cryphonectria & parasitica & MUCL 007956 & - & - \\
\hline & Disporotrichum & dimorphosporum & MUCL 019341 & - & - \\
\hline & Fusarium & venenatum & MUCL 055417 & - & - \\
\hline & Hansenula & polymorpha & MUCL 027761 & - & - \\
\hline & Humicola & insolens & MUCL 015010 & - & - \\
\hline & Kluyveromyces & lactis & IHEM 02051 & - & - \\
\hline & Leptographium & procerum & MUCL 008094 & - & - \\
\hline & Mucor & javanicus & IHEM 05212 & - & - \\
\hline & Penicillium & camemberti & IHEM 06648 & - & - \\
\hline & Penicillium & chrysogenum & IHEM 03414 & - & - \\
\hline & Penicillium & citrinium & IHEM 26159 & - & - \\
\hline & Penicillium & decumbens & IHEM 05935 & - & - \\
\hline & Penicillium & funiculosum & MUCL 014091 & - & - \\
\hline & Penicillium & multicolor & CBS 501.73 & - & - \\
\hline & Penicillium & roqueforti & IHEM 20176 & - & - \\
\hline & Pichia & pastori & MUCL 027793 & - & - \\
\hline & Rhizoтисог & miehei & IHEM 26897 & - & - \\
\hline & Rhizopus & niveus & ATCC 200757 & - & - \\
\hline & Rhizopus & oryzae & IHEM 26078 & - & - \\
\hline & Saccharomyces & cerevisiae & IHEM 25104 & - & - \\
\hline & Sporobolomyces & singularis & MUCL 027849 & - & - \\
\hline & Talaromyces & cellulolyticus/pinophilus & IHEM 16004 & - & - \\
\hline & Talaromyces & emersonii & DSM 2432 & - & - \\
\hline & Trametes & hirsuta & MUCL 030869 & - & - \\
\hline & Trichoderma & citrinoviride & IHEM 25858 & - & - \\
\hline & Trichoderma & longibrachiatum & IHEM 00935 & - & - \\
\hline & Trichoderma & reesei & IHEM 05651 & - & - \\
\hline & Trichoderma & viride & IHEM 04146 & - & - \\
\hline \multirow[t]{21}{*}{ Bacteria } & Arthrobacter & ramosus & LMG 17309 & - & - \\
\hline & Bacillus & amyloliquefaciens & LMG 98140 & - & $(+)$ \\
\hline & Bacillus & brevis & LMG 7123 & - & - \\
\hline & Bacillus & cereus* & ATCC 14579 & - & - \\
\hline & Bacillus & circulans & LMG 6926 T & - & - \\
\hline & Bacillus & coagulans & LMG 6326 & - & - \\
\hline & Bacillus & firmus & LMG 7125 & - & - \\
\hline & Bacillus & flexus & LMG 11155 & - & - \\
\hline & Bacillus & lentus & TIAC 101 & - & - \\
\hline & Bacillus & licheniformis & LMG $6933 \mathrm{~T}$ & - & - \\
\hline & Bacillus & megaterium & LMG 7127 & - & - \\
\hline & Bacillus & pumilus & DSMZ 1794 & - & - \\
\hline & Bacillus & smithii & LMG 6327 & - & - \\
\hline & Bacillus & subtilis & LMG $7135 \mathrm{~T}$ & - & $(+)$ \\
\hline & Bacillus & subtilis & W04-510 & - & $(+)$ \\
\hline & Bacillus & subtilis & E07-505 & - & $(+)$ \\
\hline & Bacillus & subtilis & $\mathrm{S} 10005$ & - & $(+)$ \\
\hline & Bacillus & subtilis & SUB033 & - & $(+)$ \\
\hline & Bacillus & subtilis & BNB54 & - & $(+)$ \\
\hline & Bacillus & subtilis & GMM from RASFF2014.1249 & + & + \\
\hline & Bacillus & velezensis & LMG 12384 & - & - \\
\hline
\end{tabular}

addition, as positive controls, the GM Bacillus subtilis (RASFF2014.1249) strain and the plasmid pLS1 were used. For each result, the experiment was carried out in triplicate for the real-time PCR method and in duplicate for the conventional PCR method. The wild-type microbial species carrying potentially the targeted tet- $L$ genes, according to Supplementary file 1 , are indicated by an asterisk 
Table 2 (continued)

\begin{tabular}{|c|c|c|c|c|c|}
\hline Kingdom & Genus & Species & Strain number & Real-time PCR & Conventional PCR \\
\hline & Bacillus & velezensis & LMG 17599 & - & $(+)$ \\
\hline & Bacillus & velezensis & LMG 22478 & _- & $(+)$ \\
\hline & Bacillus & velezensis & LMG 23203 & - & $(+)$ \\
\hline & Bacillus & velezensis & LMG 26770 & - & - \\
\hline & Bacillus & velezensis & LMG 27586 & - & $(+)$ \\
\hline & Cellulosimicrobium & cellulans & LMG 16121 & - & - \\
\hline & Corynebacterium & glutamicum & LMG 3652 & - & - \\
\hline & Enterococcus & faecium* & LMG 9430 & - & - \\
\hline & Escherichia & coli & LMG2092T & - & - \\
\hline & Geobacillus & caldoproteolyticus & DSM 15730 & - & - \\
\hline & Geobacillus & pallidus & LMG $11159 \mathrm{~T}$ & - & - \\
\hline & Geobacillus & stearothermophilus & LMG $6939 \mathrm{~T}$ & - & - \\
\hline & Klebsiella & pneumonia* & LMG $3113 \mathrm{~T}$ & - & - \\
\hline & Lactobacillus & casei & LMG 6904 & - & - \\
\hline & Lactobacillus & fermentum & LMG 6902 & - & - \\
\hline & Lactobacillus & plantarum & LMG 9208 & - & - \\
\hline & Lactobacillus & rhamnosus & LMG 18030 & - & - \\
\hline & Lactococcus & lactis & LMG $6890 \mathrm{~T}$ & - & - \\
\hline & Leuconostoc & citreum & LMG 9824 & - & - \\
\hline & Microbacterium & imperiale & LMG 20190 & - & - \\
\hline & Paenibacillus & alginolyticus & LMG 18723 & - & - \\
\hline & Paenibacillus & macerans & LMG 6324 & - & - \\
\hline & Protaminobacter & rubrum & CBS 574.77 & - & - \\
\hline & Pseudomonas & amyloderamosa & ATCC-21262 & - & - \\
\hline & Pseudomonas & fluorescens & LMG1794T & - & - \\
\hline & Pullulanibacillus & naganoensis & LMG 12887 & - & - \\
\hline & Streptomyces & aureofaciens & LMG 5968 & - & - \\
\hline & Streptomyces & mobaraensis & DSM 40847 & - & - \\
\hline & Streptomyces & murinus & LMG 10475 & - & - \\
\hline & Streptomyces & netropsis & LMG 5977 & - & - \\
\hline & Streptomyces & rubiginosus & LMG20268 & - & - \\
\hline & Streptomyces & violaceoruber & LMG 7183 & - & - \\
\hline & Streptoverticillium & mobaraense & CBS 199.75 & - & - \\
\hline Other & Plasmid & pLS1 & Turgeon et al. 2008 & + & + \\
\hline
\end{tabular}

content/validation-qualitative-pcr-methods-singlelaboratory).

Microbial fermentation products commercialized on the EU market were collected (Table 4, Supplementary files 4$5)$. The feed additive matrices were sampled by the French competent authorities (sample no. 1) and by the Belgian Federal Agency for the Safety of the Food Chain (FASFC) (samples no. 2-3). The feed additive matrices corresponding to the samples no. 1 and 2 were previously notified for a contamination with an unauthorized GM B. subtilis strain producing vitamin $\mathrm{B} 2$, or the associated recombinant DNA (RASFF2014.1249 and RASFF2019.3216). This GMM was previously characterized as harbouring AMR genes conferring CmR, KanR and TetR (Barbau-Piednoir et al. 2015a, 2015b; Berbers et al. 2020; Paracchini et al. 2017). The food enzyme preparations were sampled by the French competent authorities (samples no. 4-5) and by the Transversal Applied activities in Genomics (TAG) unit from Sciensano (sample no. 6). These food enzyme preparations contained either a low temperature alpha-amylase (sample no. 4), a phytase (sample no. 5) or a neutral protease (sample no. 6). The latter
(Pureferm, The Alchemist's Pantry) was previously notified (RASFF2019.3332) for a contamination with a viable GM $B$. velezensis strain harbouring the aadD gene conferring KanR (Fraiture et al. 2020c).

\section{DNA Extraction, Concentration and Purity}

DNA from microbial strains and commercialized microbial fermentation products was extracted as previously described (Fraiture et al. 2020a, 2020b). DNA concentration was measured by spectrophotometry using Nanodrop® 2000 (ThermoFisher), and DNA purity was evaluated using the A260/A280 and A260/A230 ratios.

\section{Bacterial Viability Test}

In $250 \mathrm{ml}$ of Brain-Heart Infusion broth (Sigma-Aldrich), $1 \mathrm{~g}$ of the sample no. 4 (food enzyme preparation of a low temperature alpha-amylase) was added for $48 \mathrm{~h}$ of incubation. From this culture, $100 \mu \mathrm{l}$ was plated on nutrient agar (SigmaAldrich) and incubated for $48 \mathrm{~h}$. Growing conditions were 
Table 3 Sensitivity assessment of the proposed strategy targeting the tet $L$ gene (GenBank: D00946.1). For each real-time PCR and conventional PCR result, the experiment was carried out in 12 replicates (Supplementary files 3, 7-8). For each tested DNA concentration from GM Bacillus subtilis RASFF2014.1249 strain, the corresponding estimated full genome copy number is indicated. The presence and absence of amplification of the targeted tet $L$ genes are respectively symbolized by "+" and "-". The number of positive replicate(s) out of the 12 replicates tested is indicated. For real-time PCR results, the means of the observed $C_{q}$ are indicated under brackets

\begin{tabular}{llll}
\hline DNA concentration $(\mathrm{ng})$ & Estimated full genome copy number & Real-time PCR & Conventional PCR \\
\hline 0.25 & 55,000 & $+(12 / 12)\left(C_{q} 23.5\right)$ & $+(12 / 12)$ \\
0.0025 & 550 & $+(12 / 12)\left(C_{q} 30.6\right)$ & $+(12 / 12)$ \\
0.00025 & 55 & $+(12 / 12)\left(C_{q} 33.7\right)$ & $+(12 / 12)$ \\
0.00005 & 11 & $+(12 / 12)\left(C_{q} 35.6\right)$ & $+(12 / 12)$ \\
0.000025 & 5 & $+(6 / 12)\left(C_{q} 38.3\right)$ & $-(0 / 12)$ \\
0.0000025 & 1 & $-(0 / 12)$ & $-(0 / 12)$ \\
0 & 0 & $-(0 / 12)$ & $-(0 / 12)$ \\
\hline
\end{tabular}

performed at the adequate temperature and oxygen conditions (Barbau-Piednoir et al. 2015b).

\section{Results and Discussion}

\section{Development of the PCR-Based Strategy to Detect and Evaluate the Presence of the Full-Length tetL Gene}

To develop the proposed PCR-based strategy, the natural occurrence of the tetL gene (GenBank: D00946.1) in wild-type micro-organisms was first investigated in order to assess its GMM discriminative power. By blasting this AMR gene against the NCBI Refseq genomic database, a few wild-type bacterial species, with an identity and recovery of $100 \%$, were listed, including mainly Enterococcus and Staphylococcus species (Supplementary file 1). Thanks to its limited presence in wild-type microbial strains, this AMR gene represents a target of choice to detect GMM. Among the microbial species reported by EFSA Panel on Biological Hazards (2017) as being used to produce food end feed enzymes, additives and flavourings (Table 1), only three of them (Bacillus cereus, Enterococcus faecium and Klebsiella pneumonia) were identified as potentially naturally harbouring the targeted tet $L$ gene. Given tetracycline belongs to antibiotics reported by the World Health Organization (WHO) as being highly important for human and veterinary uses, the presence, both natural and artificial, of the tet $L$ gene in food and feed give rise to health concerns, strongly highlighting the importance to use the proposed PCR-based strategy (Hudson et al. 2017; Tacconelli et al. 2018; WHO 2018).

The proposed PCR-based strategy was initially developed using the vitamin B2-producing GM B. subtilis RASFF2014.1249 strain and the plasmid pLS1 that are both carrying the AMR gene of interest (Table 2). This strategy consists of two main successive steps. The potential presence of the tet $L$ gene is firstly screened by amplifying $114 \mathrm{bp}$ of this AMR gene by real-time PCR (Table 1). The presence of its full-length is secondly evaluated by amplifying $1053 \mathrm{bp}$ of this AMR gene by conventional PCR. The latter was designed to cover the largest fragment of the tet $L$ gene possible taking into account method performance criteria compatible with GMO routine analysis (Table 1). After sequencing, the generated PCR products are
Table 4 Applicability assessment of the proposed strategy targeting the tet-L gene (GenBank: D00946.1) using commercialized microbial fermentation products. Each sample was tested at a concentration of $10 \mathrm{ng}$ in duplicate. The presence or absence of PCR amplification is respectively symbolized by "+”" or "-". For real-time PCR results, the means of the observed $C_{q}$ are indicated under brackets. In case no positive signal are observed in real-time-PCR, the subsequent conventional PCR is not performed, symbolized by "NA" (not applicable)

\begin{tabular}{llll}
\hline Samples & & Real-time PCR & Conventional PCR \\
\hline 1 & Feed additive - vitamin B2 (RASFF2014.1249) & $+\left(C_{q} 18\right)$ & + \\
2 & Feed additive - vitamin B2 (RASFF2019.3216) & $+\left(C_{q} 39.1\right)$ & - \\
3 & Feed additive - vitamin B2 & - & NA \\
4 & Food enzyme - low temperature alpha-amylase & $+\left(C_{q} 30.5\right)$ & + \\
5 & Food enzyme - phytase & $+\left(C_{q} 36.3\right)$ & - \\
6 & Food enzyme - neutral protease (RASFF2019.3332) & NA \\
\hline
\end{tabular}


characterized, allowing confirming the identity of the targeted AMR gene. The performance of the proposed PCR-based strategy was assessed, both for the real-time PCR and the conventional PCR methods. In term of specificity, ninety-one wild-type microbial species, reported as being used by the food and feed industry to produce enzymes, additives and flavourings, were tested (EFSA Panel on Biological Hazards 2017; Fraiture et al. 2020c). In term of sensitivity, DNA from the GM $B$. subtilis strain 2014-3557 was tested at different estimated full genome copy numbers $\left(55 \times 10^{3}, 550,55,11,5,1\right.$ and 0$)$.

On the one hand, the real-time PCR method was evaluated as specific because a positive signal was observed for positive controls while none of the tested wild-type microbial species presented a PCR amplification (Table 2, Supplementary file 3). This list of wild-type microbial species included Bacillus cereus, Enterococcus faecium and Klebsiella pneumonia that could naturally harbour the tet $L$ gene according to the preliminary in silico analysis (Table 2, Supplementary file 1). Moreover, the sensitivity of the realtime PCR method was successfully evaluated given that a positive signal for all 12 replicates tested was observed up to 11 estimated full genome copies of the target as well as the $\mathrm{LOD}_{95 \%}$ was determined at 16.7 estimated full genome copies of the target (Table 3, Supplementary files 7-8).

On the other hand, the conventional PCR method presented, for positive controls, a PCR amplicon at the expected size and with the expected sequence (Table2, Supplementary files 2 and 5). Regarding the wild-type microbial species tested, no PCR amplification was observed for all of them, except for $B$. amyloliquefaciens, B. subtilis and certain $B$. velezensis strains (Table 2, Supplementary file 2). Based on the preliminary in silico analysis, none of the latter bacterial species was expected to naturally harbour the targeted AMR gene (Supplementary file 1). Following the subsequent sequencing analysis, these amplicons presenting the expected size were characterized as corresponding to tet $L$ genes carried by Bacillus strains, with an identity varying from 94.83 to $97.81 \%$ (Supplementary file 6A-B). In comparison with the targeted tet $L$ gene (GenBank: D00946.1), these sequences were only presenting an identity going from 74.41 to $76.92 \%$, consequently allowing a GMM discrimination (Supplementary file 6C). Therefore, the second step of the proposed PCR-based strategy was considered as specific in reason of the possible characterization at the sequence level of any PCR amplifications observed. In addition, in the proposed PCR-based strategy, the conventional PCR associated to the sequencing analysis is only performed when a positive signal is observed during the real-time PCR screening. Since it was not the case for these microbial strains, the likelihood to encounter such a situation seems very limited (Table 2). Concerning its sensitivity, the conventional PCR method was assessed positively in reason of the generation, up to 11 estimated full genome copies of the target, of a single amplicon at the expected size and with the expected sequence for all 12 replicates tested. Moreover, the $\mathrm{LOD}_{95 \%}$ was determined at 30.8 estimated full genome copies of the target (Table 3, Supplementary files 4-5, 7-8).

\section{Applicability of the PCR-Based Strategy Targeting the tetL Gene}

To investigate the applicability of the proposed PCR-based strategy targeting the tetL gene (GenBank: D00946.1), six microbial fermentation products, either feed additives (samples no. 1-3) or food enzyme preparations (samples no. 4-6), commercialized on the EU market were tested (Table 4).

Using the real-time PCR technology, each sample was initially screened for the potential presence of the targeted AMR gene. Among these microbial fermentation products, a negative signal was observed for the samples no. 3 and 6 while the samples no. 1-2 and 4-5 presented a positive signal (Table 4). For these positive samples, different levels of contamination with the targeted AMR gene were indicated by the real-time PCR analysis. More precisely, based on the generated $C_{q}$ values that are below or above the $C_{q}$ value observed for the LOD ( 35) (Table 3), a high, for the samples no. 1 and 4, or a low, for the samples no. 2 and 5, contamination levels were respectively observed (Table 4 ).

Following its detection in the samples no. 1-2 and 4-5, the integrity of the full-length $t e t L$ gene was investigated using the developed conventional PCR method. For the microbial fermentation products presenting a low contamination of the targeted AMR gene, being the samples no. 2 and 5, no amplification was observed (Table 4, Supplementary file 4). For the samples no. 1 and 4, presenting a high contamination of the targeted AMR gene, a single amplicon at the expected size (1053 bp) was observed (Table 4, Supplementary file 4). According to the estimated LOD (Table 3), such results were expected. Based on their characterization, the sequences of the generated amplicons were confirmed as similar to the targeted tet $L$ gene reference sequence (GenBank: D00946.1) (Supplementary file 5). The presence of the full-length tet $L$ gene, commonly harboured by GM bacteria used to produce food and feed fermentation products, was consequently demonstrated, raising questions about the food and feed chain safety (Fraiture et al. 2020b).

According to all these results, the applicability of the proposed PCR-based strategy targeting the tetL gene was thus successfully evaluated to highlight suspicious commercialized microbial fermentation products contaminated with unauthorized GMM or associated recombinant DNA. On this basis, additional investigations were performed for the samples no. 1 and 4. For the sample no. 1, previous studies have shown the characterization of unnatural associations by whole-genome sequencing (WGS) applied on the viable GM strain isolated from the commercialized product, indubitably proving the 
presence of GMM and leading to the RASFF2014.1249 notification (Barbau-Piednoir et al. 2015a, 2015b; Berbers et al. 2020; Paracchini et al. 2017). For the sample no. 4, no bacterial isolate was observed under the tested condition, excluding the subsequent application of the WGS approach previously used for the sample no. 1. In this case, culture independent approaches are therefore needed, such as DNA walking and metagenomics (Fraiture et al. 2017, 2018, 2019a, 2019b, 2020c). This way, the presence of living GMM or associated recombinant DNA, via the sequence characterization of transgenic flanking regions and unnatural associations of elements, could be confirmed. However, such alternative approaches are currently not yet available.

\section{Conclusion}

In this study, the previously proposed PCR-based strategy, allowing to both screen the presence of key AMR genes and to determine the potential presence of GMM, was strengthened. For this purpose, in addition to the initially targeted cat (GenBank: NC_002013.1) and aadD (GenBank: M19465.1) genes, the tet- $L$ gene (GenBank: D00946.1) conferring TetR was selected as key target (Fraiture et al. 2020b), allowing to cover approximately $90 \%$ of potential GMM contaminations in commercialized microbial fermentation products.

According to recent studies and the present one, several commercialized microbial fermentation products have been observed as being contaminated with AMR genes and living GMM harbouring AMR genes (Barbau-Piednoir et al. 2015a, 2015b; Berbers et al. 2020; Fraiture et al. 2020a, 2020b, 2020c; Paracchini et al. 2017; RASFF portal). On this basis, concerns related to the freedom of choice of the consumers, the traceability and the safety of the food and feed chain have been raised. In contrast to microbial fermentation products, such concerns have been highly diminished for GM plants. On the one hand, to guarantee the freedom of choice for consumers, an identification method specific to the commercialized GM plant provided by the developer is mandatory, allowing enforcement laboratories to control the traceability of GM plants and derived products authorized and placed on the EU market (Regulation (EC) 1829/2003; Regulation (EC) 1830/2003). On the other hand, to ensure the safety of the food and feed chain, the absence of AMR genes belonging to the groups II and III, including AMR genes conferring $\mathrm{CmR}$ and TetR, is mandatory in GM plants (EFSA 2004). It has been established by the competent authorities in reason of the low occurrence of these AMR genes in the environment, allowing the prevention of the potential hazardous effects for the public health and environment. Consequently, the facts that no method specific to GMM are currently available, and a precautionary principle for the use of AMR genes is not applied for microbial fermentation products, are clearly a matter that is fraught with controversy.
In this context, our strengthened PCR-strategy represents therefore a crucial tool for a first line GMM screening for enforcement laboratories in order to inform the competent authorities in case microbial fermentations products commercialized on the EU market are contaminated by AMR genes and thus suspected to contain GMM.

Acknowledgements The Sanger sequencing was performed at the Transversal activities in Applied Genomics Service at Sciensano. The authors would like to thank Patrick Philipp (Service Commun des Laboratoires, France) for his kindness to provide the RASFF2014.1249 vitamin B2 feed additive matrix and commercialized food enzyme preparations, Marc Heyndrickx (ILVO, Belgium) for his kindness to provide bacterial strains as well as Nathalie Turgeon and Caroline Duchaine (Université Laval, Canada) for their kindness to provide the plasmid pLS1.

Funding Information The research that yielded these results, was funded both by the Belgian Federal Public Service of Health, Food Chain Safety and Environment through the contract [RT 17/5 SPECENZYM] and by the Transversal activities in Applied Genomics (TAG) Service from Sciensano.

\section{Compliance with Ethical Standards}

Conflict of Interest Marie-Alice Fraiture declares that she has no conflict of interest. Marie Deckers declares that she has no conflict of interest. Nina Papazova declares that she has no conflict of interest. Nancy H. C. Roosens declares that she has no conflict of interest.

Ethical Approval This article does not contain any studies with human participants or animals performed by any of the authors.

\section{Informed Consent Not applicable.}

Open Access This article is licensed under a Creative Commons Attribution 4.0 International License, which permits use, sharing, adaptation, distribution and reproduction in any medium or format, as long as you give appropriate credit to the original author(s) and the source, provide a link to the Creative Commons licence, and indicate if changes were made. The images or other third party material in this article are included in the article's Creative Commons licence, unless indicated otherwise in a credit line to the material. If material is not included in the article's Creative Commons licence and your intended use is not permitted by statutory regulation or exceeds the permitted use, you will need to obtain permission directly from the copyright holder. To view a copy of this licence, visit http://creativecommons.org/licenses/by/4.0/.

\section{References}

Bacanli M, Basacan N (2019) Importance of antibiotic residues in animal food. FCT 125:462-466

Barbau-Piednoir E, De Keersmaecker SCJ, Wuyts V, Gau C, Pirovano W, Costessi A, Philipp P, Roosen NH (2015a) Genome sequence of the EU-unauthorized genetically modified Bacillus subtilis strain 2014-3557 overproducing riboflavin, isolated from an imported lot of vitamin B2 80\% feed additive. Genome Announc 3:e00214 e00215 
Barbau-Piednoir E, De Keersmaecker SCJ, Delvoye M, Gau C, Philipp P, Roosens NHC (2015b) Use of next generation sequencing data to develop a qPCR method for specific detection of EU-unauthorized genetically modified Bacillus subtilis overproducing riboflavin. BMC Biotechnol 15:103

Berbers B, Saltykova A, Garcia-Graells C, Philipp P, Arella F, Marchal K, Winand R, Vanneste K, Roosens NHC, De Keersmaecker SCJ (2020) Combining short and long read sequencing to characterize antimicrobial resistance genes on plasmids applied to an unauthorized genetically modified Bacillus. In: Combining short and long read sequencing to characterize antimicrobial resistance genes on 2 plasmids applied to an unauthorized genetically modified Bacillus. Sci. Rep, Accepted

Deckers D, Vanneste K, Winand R, De Keersmaecker S, Denayer S, Heyndrickx M, Deforce D, Fraiture MA, Roosens NH (2020) Strategy for the identification of micro-organisms producing food and feed products: bacteria producing food enzymes as study case. Food Chem 305:125431

EFSA (2004) Opinion of the scientific panel on genetically modified organisms on the use of antibiotic resistance genes as marker genes in genetically modified plants. Ej EFSA journal 48:1-18

EFSA Panel on Biological Hazards (2017) Scientific opinion on the update of the list of QPS-recommended biological agents intentionally added to food or feed as notified to EFSA. ej EFSA Journal 15:4664

Fraiture MA, Herman P, Papazova N, De Loose M, Deforce D, Ruttink T, Roosens NHC (2017) An integrated strategy combining DNA walking and NGS to detect GMO. Food Chem 232:351-358

Fraiture MA, Saltykova A, Hoffman S, Winand R, Deforce D, Vanneste K, De Keersmaecker S, Roosens NHC (2018) Nanopore sequencing technology: a new route for the fast detection of unauthorized GMO. Sci Rep 8:7903

Fraiture MA, Papazova N, Vanneste K, De Keersmaecker SCJ, Roosens NHC (2019a) GMO detection and identification using nextgeneration sequencing. In: Burns M, Foster L, Walker M (eds) DNA techniques to verify food authenticity: applications in food fraud. Royal Society of Chemistry

Fraiture MA, Ujhelyi G, Ovesná J, Van Geel D, De Keersmaecker SCJ, Saltykova A, Papazova N, Roosens N (2019b) MinION sequencing technology to characterize unauthorized GM petunia plants circulating on the European Union market. Sci Rep 9:7141

Fraiture MA, Bogaerts B, Winand R, Deckers M, Papazova N, Vanneste K, De Keersmaecker SCJ, Roosens NHC (2020a) Next-generation sequencing: a key tool to identify unauthorized genetically modified microorganisms in food enzyme preparations. Submitted

Fraiture MA, Deckers M, Papazova N, Roosens NHC (2020b) Detection strategy targeting a chloramphenicol resistance gene from genetically modified bacteria in food and feed products. Food Control 18: 106873

Fraiture MA, Deckers M, Papazova N, Roosens NHC (2020c) Are antimicrobial resistance genes key targets to detect genetically modified microorganisms in fermentation products? Submitted

Grohmann L, Broll H, Dagand E, Hildebrandt S, Hübert P, Kiesecker H, Lieske K, Mäde D, Mankertz J, Reiting R, Schulze M, Speck B, Uhlig S, Wahler D, Waiblinger HU, Woll K, Zur K (2016) Guidelines for the validation of qualitative real-time PCR methods by means of a collaborative study. Technical report BVL 1

Hudson JA, Frewer LJ, Jones G, Brereton PA, Whittingham MJ, Stewart $\mathrm{G}$ (2017) The agri-food chain and antimicrobial resistance. A review Trends Food Sci Technol 69:131-147
Lacks S, Lopez P, Greenberg B, Espinosa M (1986) Identification andanalysis of genes for tetracycline resistance and replication functions in the broad-host-range plasmid pLS1. J Mol Biol 192:753765

Munita JM, Arias CA (2016) Mechanisms of antibiotic resistance. Microbiol Spectr 4:2

Paracchini V, Petrillo M, Reiting R, Angers-Loustau A, Wahler D, Stolz A, Schönig B, Matthies A, Bendiek J, Meinel DM, Pecoraro S, Busch U, Patak A, Kreysa J, Grohmann L (2017) Molecular characterization of an unauthorized genetically modified Bacillus subtilis production strain identified in a vitamin B2 feed additive. Food Chem 230:681-689

RASFF portal < https://webgate.ec.europa.eu/rasff-window/portal/? event=SearchForm\&cleanSearch $=1>$

Regulation (EC) (1829/2003) Of the European Parliament and of the council of 22 September 2003 on genetically modified food and feed. Off J Eur Union L268:1-23

Regulation (EC) (1830/2003) Of the European Parliament and of the council of 22 September 2003 concerning the traceability and labelling of genetically modified organisms and the traceability of food and feed products produced from genetically modified organisms and amending directive 2001/18/EC. Off J Eur Union L268:24-28

Rozwandowicz M, Brouwer MSM, Fischer J, Wagenaar JA, GonzalezZorn B, Guerra B, Mevius DJ, Hordijk J (2018) Plasmids carrying antimicrobial resistance genes in Enterobacteriaceae. J Antimicrob Chemother 73:1121-1137

Sharma C, Rokana N, Chandra M, Singh BP, Gulhane RD, Gill JPS, Ray P, Puniya AK, Panwar H (2018) Antimicrobial resistance: its surveillance, impact, and alternative management strategies in dairy animals. Front Vet Sci 4:237

Tacconelli E, Carrara E, Savoldi A, Harbarth S, Mendelson M, Monnet DL, Pulcini C, Kahlmeter G, Kluytmans J, Carmeli Y, Ouellette M, Outterson K, Patel J, Cavaleri M, Cox E, Houchens C, Grayson L, Hansen P, Singh N, Theuretzbacher U, Magrini N, the WHO Pathogens Priority List Working Group (2018) Discovery, research, and development of new antibiotics: the WHO priority list of antibiotic-resistant bacteria and tuberculosis. Lancet Infect Dis 18: 318-327

Turgeon N, Laflamme C, Ho J, Duchaine C (2008) Evaluation of the plasmid copy number in $\mathrm{B}$. cereus spores, during germination, bacterial growth and sporulation using real-time PCR. Plasmid 60:118124

Uhlig S, Frost K, Colson B, Simon K, Made D, Reiting R, Gowig P, Grohmann L (2015) Validation of qualitative PCR methods on the basis of mathematical-statistical modelling of the probability of detection. Accred Qual Assur 20:75-83

von Wrighta A, Bruce A (2003) Genetically modified microorganisms and their potential effects on human health and nutrition. Trends Food Sci Technol 14:264-276

WHO (2018) Critically important antimicrobials for human medicine, 6th revision. <https://apps.who.int/iris/bitstream/handle/10665/312266/ 9789241515528-eng.pdf?ua=1>

Xiong W, Sun Y, Zeng Z (2018) Antimicrobial use and antimicrobial resistance in food animals. Environ Sci Pollut R 25:18377-18384

Publisher's Note Springer Nature remains neutral with regard to jurisdictional claims in published maps and institutional affiliations. 